\title{
Astragaloside IV enhances memory and modulates hippocampal synaptic plasticity by decreasing GABAergic inhibition through EGR-1 mediated BDNF/TrkB signaling pathway in mice
}

\section{Fei Huang}

Shanghai University of Traditional Chinese Medicine

Yunyi Lan

Shanghai University of Traditional Chinese Medicine Jin Zhou

Shanghai University of Traditional Chinese Medicine Liu Yang

Shanghai University of Traditional Chinese Medicine Hao Guan

Shanghai University of Traditional Chinese Medicine Hailian Shi

Shanghai University of Traditional Chinese Medicine

Hui Wu

Shanghai University of Traditional Chinese Medicine

\section{Zhibi Hu}

Shanghai University of Traditional Chinese Medicine

Xiaojun Wu ( $\nabla$ xiaojunwu320@126.com)

Shanghai University of Traditional Chinese Medicine https://orcid.org/0000-0001-6554-5341

\section{Research}

Keywords: astragaloside IV, early growth response protein 1, gamma-aminobutyric acid, memory, synaptic plasticity

Posted Date: June 18th, 2020

DOl: https://doi.org/10.21203/rs.3.rs-35057/v1

License: (c) (1) This work is licensed under a Creative Commons Attribution 4.0 International License. Read Full License 


\section{Abstract \\ Background}

Astragaloside IV (ASIV) is one of the saponins isolated from Astragalus membranaceus, a widely used traditional Chinese medicine and a health product sold all over the world. However, so far, the effect of ASIV on GABAergic synaptic transmission has not been elucidated yet. In the present study, the effect of ASIV on memory and hippocampal synaptic plasticity was investigated in mice and down-regulated early growth response protein 1 (EGR-1) knockout mice.

\section{Methods}

Behavior tests including radial-arm maze test and shuttle-box test, liquid chromatography-tandem mass spectrometry, western blotting analysis, quantitative PCR, electrophysiological recording, and electron microscopy were used in this study. The difference of data was detected by unpaired student t-test or two-factor analysis of variance (ANOVA) or Mann-Whitney $U$ test.

\section{Results}

ASIV was shown to enhance the learning and memory of mice in behavior tests, such as radial-arm maze test and shuttle-box test, as well as the synaptic plasticity in electrophysiological experiments. Moreover, it significantly reduced the concentration of gamma-aminobutyric acid (GABA) and the expression of glutamate decarboxylase 2 (GAD65) in mouse hippocampus, which was accompanied with decreased ratio of inhibitory synapses, and EGR-1, brain-derived neurotrophic factor (BDNF) and tyrosine receptor kinase $B$ (TrkB). When EGR-1 was knocked out, the promotive effects of ASIV on memory and synaptic plasticity, as well as the inhibitory effects on GAD65, BDNF and TrkB, were abolished. In addition, ASIV was found to down-regulate the pre-existing EGR-1 baseline to better adapt to the learning stimuli.

\section{Conclusions}

Together, these results demonstrated a novel role of ASIV in enhancing memory and modulating hippocampal synaptic plasticity by decreasing GABAergic inhibition through EGR-1 mediated BDNF/TrkB signaling pathway in mice.

\section{Introduction}

Hippocampal synaptic plasticity is vital to memory formation and retention. Long-term potentiation (LTP) and long-term depression (LTD) are in-depth studies of the process to understand the synaptic basis of learning and memory [1]. LTD is modulated by the gamma-aminobutyric acid (GABA) [2], which is the main inhibitory neurotransmitter in mammals and is widely distributed in the central nervous system 
(CNS) of mammals. GABA receptors mediate inhibitory nerve transfer, preventing neurons from overexciting in the adult brain (Suzdak \& Jansen, 1995). LTD seems to be a supplement to the candidate memory, which is independent of $G A B A$ type $A$ receptor $\left(G A B A_{A} R\right)$ activation [2]. Inhibitory $G A B A_{A} R$ activity regulates $G A B A e r g i c$ synaptic plasticity through extracellular signal-regulated kinases $(E R K)$ and brain-derived neurotrophic factor (BDNF) signaling [3]. BDNF is a member of the neurotrophic family, which is found mainly in the hippocampus, amygdala, cortex and cerebellum. It is synthesized by neurons and glial cells and is involved in the survival, differentiation and regeneration of neurons by binding to high affinity receptor, (TrkB) $[4,5]$.

Early growth response protein 1 (EGR-1), also known as Zif268, Zenk, Krox-24, NGF1-A, TIS8, and Krox-24, belongs to the early growth response (EGR) gene family and is also described as induced transcription factor [6]. It plays a vital role in the maintenance of synaptic plasticity including LTP [7, 8] and LTD [9], which is well known to be essential for many cognitive functions. And tremendous evidence demonstrated that EGR-1 actively participates in different memory forms as well as different memory processes, from learning memory consolidation $[10,11]$ and system consolidation $[12,13]$ to reconsolidation $[14,15]$.

Astragaloside IV (ASIV) is a saponin molecule found in Astragalus membranaceus (Fisch.) Bge, an herbal medicine proverbially used in China and a health product widely sold in Europe. Multiple pharmacological activities of ASIV have been disclosed, such as anti-oxidation [16] anti-apoptosis [17], anti-inflammation [18], and immuno-regulation [19, 20]. And ASIV also shows prominent neuroprotective effects in multifarious CNS injuries, including cerebral ischemic-reperfusion injury [21-23], Parkinson's disease [24] and Alzheimer's disease [25, 26]. However, so far, the study of the effect of ASIV on synaptic plasticity and memory is lacking. In this study, we firstly reported that ASIV could enhance memory and improve hippocampal synaptic plasticity in mice. Furthermore, our study disclosed that the effect of ASIV was achieved probably by decreasing GABAergic inhibition via EGR-1 mediated BDNF/TrkB signaling pathway. The novel findings can contribute the potential application of ASIV in neurological diseases with impaired memory.

\section{Materials And Methods}

\section{Animal and Drug Administration}

C57BL/ 6 mice (Male, $14 \sim 18 \mathrm{~g}, 4 \sim 5$ weeks old) were provided by the Laboratory Animal Center of Shanghai University of Traditional Chinese Medicine (SHUTCM, Shanghai). All experiments on animals were performed according to the protocol approved by Animal Care and Use Committee of SHUTCM and all animals received humane care (Ethical approval no. SZY201610005). Animals were acclimatized for 2 weeks before the formal behavior experiments.

Fourteen mice were injected intraperitoneally (i.p.) with ASIV (25 mg/kg, 40\% 1,2-Propanediol + 5\% Ethanol $+1 \%$ Polyethylene glycol in phosphate buffer saline solution) for five weeks, while fourteen mice 
were administered with solvent served as the control. All of the twenty-eight mice were subjected into behavioral tests. Another forty-four C57BL/ 6 mice of the same source were with only injection for further experiments; twenty-two mice received an i.p. injection of ASIV $(25 \mathrm{mg} / \mathrm{kg})$ daily for two weeks, while twenty-two mice were administered with solvent served as the control.

For LTD induction in vitro experiment, eight C57BL/6 mice (male, $12 \sim 17 \mathrm{~g}, 3 \sim 4$ weeks old) were provided by SPF biotechnology Co., Ltd (Beijing, China). Four of them were i.p. administered with ASIV $(25 \mathrm{mg} / \mathrm{kg}$ ) for two weeks, while four mice were administered with solvent served as the control.

EGR-1 ${ }^{+/-}$mice maintained on the C57BL/ 6 background was obtained from the Jackson Laboratory (Bar Harbor, ME, USA). Experiments were carried out on male EGR-1 ${ }^{-/-}$(EGR-1 KO) mice and their EGR-1 ${ }^{+/+}$ littermates (male, $14 \sim 18 \mathrm{~g}, 4 \sim 5$ weeks old) that were derived from EGR-1 ${ }^{+/-} \times \mathrm{EGR}-1^{+/-}$breeding at the same time. Fourteen EGR-1 KO mice were injected intraperitoneally (i.p.) with ASIV ( $25 \mathrm{mg} / \mathrm{kg}$ ) for five weeks, while fourteen EGR-1 KO mice were administered with solvent served as the control. For LTD induction in vitro experiment, three EGR-1 KO mice (12-17 g, $3 \sim 4$ weeks old) were i.p. administered with ASIV $(25 \mathrm{mg} / \mathrm{kg})$ for two weeks, while four mice were administered with solvent served as the control.

All mice were housed at room temperature $\left(25 \pm 1{ }^{\circ} \mathrm{C}\right)$ under a $12 \mathrm{~h}$ light / $12 \mathrm{~h}$ dark cycle, and fed with food and drank with water ad libitum freely. All behavioral tests were conducted in the light phase between 12:00 a.m. and 18:00 p.m. In order to avoid experimental deviation, all behavioral observers were blinded to the administration of the experimental mice. All animal experiments were conducted in accordance with the guidelines for Laboratory Animal care and Use Committee of SHUTCM and National Institutes of Health guide for the care and use of Laboratory animals (NIH Publications No. 8023, revised 1978).

\section{Behavioral Tests}

Radial-arm Maze Test (RAMT): The apparatus for radial-arm maze (RAM) (Mobiledatum Inc, Shanghai, China) consists of eight equally spaced arms (length $30 \mathrm{~cm}$, height $15 \mathrm{~cm}$, width $6 \mathrm{~cm}$ ) radiating from a central maze hub (diameter $12 \mathrm{~cm}$ ). It was made of opaque plexiglass with manually operated doors lead from the hub of the central maze to each arm. RAMT was conducted in accordance with the procedure described previously, with minor modification [27]. As shown in Fig. 1A, the mice were acclimatized to the RAM for 4 days before administrated with ASIV on day 1 . Then, they were trained to explore the RAM with four arms placed with $50 \mathrm{mg}$ bait (sugar: regular chow =1:1) from day 2 to day 6 . At the time of a week's administration, the mice were placed in the octagonal arena at the beginning of the experiment. The experiment ended when the mice explored the maze for 5 min or visited four baited arms. At the time of two weeks' administration, the test was conducted again. The maze was wiped down with $10 \%$ ethanol between each run to reduce olfactory cues. During these days, mice were given semi-food diet feeding. In these two tests, reference and working memory errors and the time required to complete the tasks were recorded and analyzed. 


\section{Shuttle-box test (SBT)}

SBT was performed following RAMT on day 22. The chamber (Mobiledatum Inc, Shanghai, China) is divided into two equal compartments connected by a gate. A light is switched on alternately in the two compartments for conditioned stimulus. The test was conducted following a procedure described by Cheng et al [28]. Briefly, each mouse was allowed to adapt to the chambers for 4 min before the formal test. At the beginning of the experiment, the mice were placed in a compartment of the shuttle-box and back to the gate. Each mouse was given 30 consecutive trials at intervals of $20 \mathrm{~s}$ (light $5 \mathrm{~s}$; interval, $3 \mathrm{~s}$; $0.2 \mathrm{~mA}$ electric shock, $5 \mathrm{~s}$; interval, $7 \mathrm{~s}$ ) for five consecutive days. The active avoidance response was recorded automatically if the mouse moved to another compartment during conditioned stimulus. At the day 35 of continuous ASIV administration, all animals received the same experimental protocol to assess memory consolidation.

\section{Neurotransmitter Analysis}

After all behavioral tests were completed; the mice as well as those administered with ASIV only for two weeks were sacrificed after anesthetized with $1.5 \%$ pentobarbitalum. Immediately, the hippocampus of mice was dissected on ice, frozen rapidly in liquid nitrogen and stored at $-80^{\circ} \mathrm{C}$ until analysis. The content of GABA in mouse hippocampus was determined by liquid chromatography-tandem mass spectrometry (LC-MS/MS) method as reported previously [29].

\section{Western Blotting Analysis}

The hippocampus of mice was homogenized, sectioned and analyzed by Western blotting. Totally thirty micrograms of protein were separated from each sample by $10 \%$ SDS-PAGE electrophoresis. After transferred to polyvinylidene fluoride membrane (GE Healthcare, Little Chalfont, Buckinghamshire, UK), the proteins were incubated with respective primary antibodies against glutamate decarboxylase 2 (GAD65) (cat: ab26113), EGR-1 (cat: ab194357), BDNF (cat: ab88901), TrkB (cat: ab101696) and GAPDH (cat: ab181602) provided by Abcam (Cambridge, MA, USA). Sequentially, the proteins were further incubated with secondary antibodies as described previously [16]. The protein bands were visualized by ECL reagent kit (cat: RPN2232, GE Healthcare) and quantified with Gel-Pro analyzer software (Media Cybernetics, L.P., MD, Rockville, USA).

\section{Quantitative PCR}

Total RNAs from mouse hippocampus were extracted using Trizol reagent (Life Technologies, Waltham, MA, USA). Afterwards, the RNA samples were reverse-transcripted into CDNA with Revert Aid First Strand cDNA Synthesis kit (Fermentas, Waltham, MA, USA). The synthesized cDNA was used as templates for quantitative real-time PCR with Universal SYBR Green/ROX qPCR Master Mix (Roche, Basel, Switzerland) 
on ABI ViiA7 quantitative real-time PCR platform (Applied Biosystems, Foster City, CA, USA). Quantification of the target gene was conducted by comparative Ct method with GAPDH as a reference gene. Primers used were listed as following: for EGR-1, 5'-AGCAGCGCCTTCAATCCTCA-3', 5'TCTCCACCATCGCCTTCTCA-3'; for GAPDH, 5'-ATGTGTCCGTCGTGGATCTGA-3', 5'ATGCCTGCTTCACCACCTTCT-3'.

\section{Electrophysiological Recording}

\section{LTD induction in vitro}

After continous i.p. injection of ASIV ( $25 \mathrm{mg} / \mathrm{kg}$ ) for two weeks from 4 weeks old, the mice's brain were removed, and three brain slices ( $350 \mu \mathrm{m}$ thick) were obtained from each mouse, covering the transverse ventral hippocampus. Slices were incubated at room temperature for at least $90 \mathrm{~min}$ in artificial cerebrospinal fluid (ACSF; containing $24 \mathrm{mmol} / \mathrm{L} \mathrm{NaCl}, 26 \mathrm{mmol} / \mathrm{L} \mathrm{NaHCO}_{3}, 2 \mathrm{mmol} / \mathrm{L} \mathrm{KCl}, 2 \mathrm{mmol} / \mathrm{L}$ $\mathrm{CaCl}_{2}, 2 \mathrm{mmol} / \mathrm{L} \mathrm{MgSO}_{4}, 1.25 \mathrm{mmol} / \mathrm{L} \mathrm{NaH}_{2} \mathrm{PO}_{4}$ and $10 \mathrm{mmol} / \mathrm{L} \mathrm{D}$-glucose) and ventilated with a mixture of $95 \%$ oxygen and $5 \%$ carbon dioxide. Subsequently, the slices were transferred to the recording chamber and inflated ACSF at a flow of $2 \mathrm{~mL} / \mathrm{min}$ rate at $(22 \pm 2){ }^{\circ} \mathrm{C}$. After the temperature $(33 \pm 1){ }^{\circ} \mathrm{C}$ and perfusion rate, field excitatory post synaptic potentials (fEPSPs) were recorded. A bipolar stimulus electrode was placed on Schaffer's collateral/commissural bundle in CA3 hippocampus, and a recording glass micropipette $(1-3 \mathrm{M} \Omega$, filled with $3 \mathrm{~mol} / \mathrm{L} \mathrm{NaCl})$ was placed on the radiator in CA1 hippocampus. AxoClamp 700B amplifier filter was set at $3 \mathrm{kHz}$, while the sampling frequency was set at $20 \mathrm{kHz}$ (Digidata 1440A, GE MDS, NY, USA). Meanwhile, the data were collected and stored with Clampex 10.3 (GE MDS company). Current intensity adjusted to $60-70 \%$ of maximal fEPSP (base lines stimulation). Low frequency paired pulse stimulations (LFPS; 25 millisecond paired pulse interval, $1 \mathrm{~Hz}$, monophasic quare pulses same as the baseline) induced LTD for $15 \mathrm{~min}$. Immediately after each single stimulus for $60 \mathrm{~s}$, the fEPSPs reaction was recorded for $60 \mathrm{~min}$. Throughout the course the stimulation intensity is maintained constant. And throughout the recording period bicuculline $(10 \mu \mathrm{mol} / \mathrm{L})$ was included in the continuous perfusion (ACSF). The slope of fEPSPs was analyzed using Clampfit (GE MDS Company) and standardized with the average baseline response. The average changes of fEPSPs in 5 min after prestimulus baseline conditions were used to compare with the average response time of the first 30-35 min after stimulation conditions for statistical purpose.

\section{Input-output $(/ / 0)$ function in vivo}

I/O curve reflects the relationship between the amplitude of fEPSP and the intensity of stimulation, which is used to evaluate the synaptic potency [30]. After continous i.p. injection of ASIV ( $25 \mathrm{mg} / \mathrm{kg})$ for two weeks from 6 weeks old, the mice were anesthetized with $25 \%$ urahtane $(1 \mathrm{~mL} / 100 \mathrm{~g})$ and fixed on the stereotaxic device (Narishige Ins, Tokyo, Japan). The location parameters of granular cell layer in DG area were $2.0 \mathrm{~mm}$ after anterior fontanel, $1.4 \mathrm{~mm}$ near midline, $1.5 \mathrm{~mm}$ deep under dura mater; and $3.8 \mathrm{~mm}$ after anterior fontanel, $3.0 \mathrm{~mm}$ near midline, $1.5 \mathrm{~mm}$ deep under dura mater. In the front fontanel, 
recording electrode and stimulating electrode (Nihon Kohden, Tokyo, Japan) were almost in a straight line. According to the above positioning parameters, drill holes in the skull with a skull drill (Minimo, Tokyo, Japan), then insert recording electrodes into the granular cell layer of DG area, and insert stimulating electrodes into performant pathway. The reference electrodes were clamped on the scalp. With $0.1 \mathrm{~mA}(0.1-2.0 \mathrm{~mA})$ as a step, the stimulation current was changed systematically to produce $\mathrm{I} / \mathrm{O}$ curve. Three responses at each current level were averaged, and the population spike (PS) amplitude was examined. The signals were transferred through the amplifier (Axon, CA, USA), and filtered by PCLab202 software (Microsignalstar, Beijing, China).

\section{Electron Microscopy}

After deeply anesthetized with $20 \%$ urethane, mice were perfused with $2.5 \%$ glutaraldehyde in $0.1 \mathrm{M}$ phosphate ( $\mathrm{pH} 7.4$ ) transcardially. The brains were dissected and post-fixed in $2.5 \%$ glutaraldehyde for $24 \mathrm{~h}$. Sequentially, they were incubated with $2 \%$ osmium tetroxide, dehydrated with series acetone and embedded with epoxy resin. The $60 \mathrm{~nm}$-thick ultrathin sections were obtained on an ultra-microtome (ultracut UCT, Leica, Wetzlar, Germany) and observed by transmission electron microscope (Tecnai G2 Spirit BioTWIN, Hongkong, China).

\section{Statistical analysis}

All data were performed through Graphpad Prism 6 (Graphpad, La Jolla, CA). The difference of measurement data and numeration data were detected by unpaired student t-test or two-factor analysis of variance (ANOVA) and Mann-Whitney $U$ test, respectively. Error bars represented the standard error of the mean (S.E.M.). P-value less than 0.05 was regarded as a significant difference.

\section{Results}

\section{ASIV enhanced the memory of mice in both RAMT and SBT}

To explore the effect of ASIV on the memory of mice, the mice were subjected to the RAMT and SBT after ASIV administration. For RAMT, the working memory and reference memory that refer to short-term memory and long-term memory respectively were analyzed. As shown in Fig. 1B and Fig. 1C, ASIV treated mice performed better in the RAMT as their working memory error times (Fig. 1B, for 1-week, $U=62.00, P$ $=0.0782$; for 2-week, $U=54.50, P=0.0358$ ) and reference memory error times were reduced significantly (Fig. 1C, for 1-week, $U=46.00, P=0.1276$; for 2-week, $U=33.00, P=0.0174$ ), compared with the control mice. Moreover, ASIV markedly increased the active avoidance times of mice in SBT (Fig. 1D, U = 30.50, $P$ $=0.0012$ ). These results showed that ASIV could enhance the memory of mice.

\section{ASIV Enervated Hippocampal GABAergic System In Mice}


To determine the effect of ASIV on the GABAergic system, the concentration of GABA and the expression of GAD65 in hippocampi of mice were examined, respectively. As shown in Fig. 2A, hippocampal GABA level in ASIV treated mice was reduced when compared with that of the control mice (for 2-week, $\mathrm{t}_{(20)}=$ $5.003, P=0.0000$; for 5-week, $\left.\mathrm{t}_{(25)}=2.507, P=0.0190\right)$. Accordingly, the expression of GAD65 in hippocampus of ASIV treated mice was significantly lower than that of the control mice (Fig. 2B and C, for 2-week, $\mathrm{t}_{(4)}=3.349, P=0.0286$; for 5 -week, $\mathrm{t}_{(4)}=2.779, P=0.0499$ ). To further investigate if ASIV could affect the strength of inhibitory synaptic transmission in hippocampus, untrathin sections obtained from blocks $(1 \mathrm{~mm} \times 1 \mathrm{~mm} \times 1 \mathrm{~mm})$ of CA3 region were subjected to electron microscopy observation. According to the reports, there are two major morphologic types of synapses, i.e. asymmetric and symmetric synapses [31, 32]. Excitatory synapses are asymmetrical synapses with significant postsynaptic density, while inhibitory synapses are symmetrical synapses with thinner postsynaptic density. And there is also another type of synapse with oblique synaptic cleft and associated membrane density that is considered to be uncharacterized synapses [33]. As displayed in Fig. 2D, excitory and inhibitory synapses could be clearly identified in the electron microscopy image. ASIV treatment for 2 weeks and 5 weeks decreased the ratio of inhibitory synapse remarkably in CA3 region (Fig. 2E, for 2week, $\mathrm{t}_{(5)}=2.632, P=0.0464$; for 5 -week, $\mathrm{t}_{(5)}=2.769, P=0.0394$ ). Since GABAergic system mainly participates in the synaptic inhibition, we next investigated the impact of ASIV on the LTD. As shown in Fig. 3 , the average fEPSP slope of the control mice was decreased from (100.4670 \pm 2.0450$)$ to $(74.4116$ $\pm 1.8078)$, while that of the ASIV treated mice was descended from (103.0129 \pm 1.8071$)$ to $(69.0670 \pm$ 1.6496). Therefore, the LTD after LFS of ASIV treated mice was significantly lower than that of the control mice $\left(\mathrm{t}_{(148)}=2.430, P=0.0163\right)$. The results suggested that ASIV could enervate hippocampal GABAergic neurotransmission.

\section{ASIV decreased the expressions of EGR-1, BDNF and TrkB in mouse hippocampus}

To explore the possible action mechanism of ASIV, the expressions of proteins, such as EGR-1, BDNF and TrkB that actively involved in the modulation of memory were detected. In Fig. 4A-C, ASIV treatment for 2 weeks and 5 weeks significantly suppressed the expressions of hippocampal EGR-1 at both mRNA (for 2week, $\mathrm{t}_{(10)}=2.730, P=0.0212$; for 5 -week, $\mathrm{t}_{(5)}=3.260, P=0.0225$ ) and protein levels (for 2-week, $\mathrm{t}_{(4)}=$ 2.817, $P=0.0480$; for 5 -week, $\mathrm{t}_{(4)}=3.587, P=0.0247$ ). Similarly, the expression of BDNF as well as its receptor, TrkB, was also decreased in mouse hippocampus after treated with ASIV for 2 weeks and 5 weeks (Fig. $5 \mathrm{~A}$ and $\mathrm{B}$, for 2-week BDNF, $\mathrm{t}_{(4)}=7,779, P=0.0015$; for 5-week BDNF, $\mathrm{t}_{(4)}=2.794, P=0.0491$; Fig. $5 \mathrm{C}$ and $\mathrm{D}$, for 2-week TrkB $\mathrm{t}_{(4)}=3.512, P=0.0249$; for 5 -week TrkB, $\mathrm{t}_{(4)}=3.203, P=0.0328$ ). The results suggested that ASIV might enhance the memory of mice through regulating the signaling pathways mediated by EGR-1, BDNF and TrkB.

\section{EGR-1 KO abrogated the memory beneficial effect of ASIV on mice in both RAMT and SBT}

To reveal the role of EGR-1 in the memory beneficial effect of ASIV on mice, EGR-1 KO mice were treated with ASIV and subjected to the RAMT and SBT using the same time line as illustrated in Fig. 1A. As 
shown in Fig. 6A and B, ASIV treatment did not reduce the working memory (for 1-week, $U=19.00, P=$ 0.2228; for 2-week, $U=43.00, P=0.6158$ ) and reference memory errors (for 1-week, $U=23.00, P=0.4815$; for 2-week, $U=35.00, P=0.2775$ ) of EGR-1 KO mice in RAMT. And ASIV treatment also did not change the active avoidance times of EGR-1 KO mice in SBT (Fig. $6 \mathrm{C}, \mathrm{U}=44.00, P=0.6684$ ). These results confirmed that EGR-1 played an indispensable role in the memory beneficial effect of ASIV.

\section{EGR-1 KO abolished the potentiation of ASIV on LTD in mice}

To further corroborate the role of EGR-1 in hippocampal GABAergic system of ASIV treated mice, the LTD response of EGR-1 KO mice treated with ASIV for 2 weeks was recorded. As shown in Fig. 7A-B, the average fEPSP slope of EGR-1 KO control mice was decreased from $(100.397 \pm 2.414)$ to $(58.474 \pm$ 1.753). By contrast, the average fEPSP slope of ASIV treated EGR-1 KO mice were descended from $(100.349 \pm 1.477)$ to $(75.653 \pm 1.708)$. Therefore, the LTD after LFS of ASIV treated EGR-1 KO mice was significantly higher than that of the vehicle treated EGR-1 KO mice $\left(\right.$ Fig. $\left.7 \mathrm{C}, \mathrm{t}_{(148)}=3.785, P=0.0002\right)$. These results demonstrated that EGR-1 KO weakened the potentiation of ASIV on LTD in mice.

\section{EGR-1 KO blocked the inhibition of ASIV on GAD65, BDNF and TrkB in mouse hippocampus}

To further validation of EGR-1 in the inhibitory effect of ASIV on GABAergic synaptic plasticity, the hippocampal protein expressions of GAD65, BDNF and TrkB were examined in EGR-1 KO mice treated with ASIV for 5 weeks. As shown in Fig. 8, ASIV treatment did not change the expression levels of GAD65 $\left(\mathrm{t}_{(6)}=0.6829, P=0.5202\right)$, BDNF $\left(\mathrm{t}_{(6)}=1.331, P=0.2317\right)$ and TrkB $\left(\mathrm{t}_{(6)}=0.2750, P=0.7958\right)$ in

hippocampus of EGR-1 KO mice, suggesting that ASIV modulated GABAergic synaptic plasticity through EGR-1.

\section{ASIV increased basic synaptic transmission and enhanced mRNA expression of EGR-1 in response to external stimuli in mice}

To test the effects of ASIV on basic synaptic transmission in the CA1 region, the I/O function of ASIV treated mice was evaluated. As illustrated in Fig. 9A, the PS amplitude of ASIV-treated mice showed the increasing tendency, especially when the stimulus current was at $1.2 \mathrm{~mA}, 1.3 \mathrm{~mA}, 1.5 \mathrm{~mA}$ and $1.6 \mathrm{~mA}(P<$ 0.1 ), suggesting that ASIV might enhance hippocampal synaptic transmission in mice.

To further understand the physiological significance of the inhibitory effect of ASIV on EGR-1, the micetreated with ASIV for 2 weeks were subjected to a single-trial SBT together with the control mice. Consequently, the hippocampal mRNA expression of EGR-1 was analyzed. In Fig. 9B, mRNA expression level of EGR-1 in both control and ASIV-treated mice was elevated. However, the increase amplitude of the mRNA expression level of EGR-1 in ASIV treated mice was greater than that in the vehicle-treated control mice $\left(t_{(11)}=2.327, P=0.0400\right)$. These results suggested ASIV could increase the response of EGR-1 to external stimuli.

\section{Discussion}


Memory formation is a complex process. This is partly due to the information is assumed to be transiently stored in working memory (short-term memory) while it is considered to integrate long-term memory permanently [34]. At present, a lot of knowledge about memory comes from the study of memory impairment, especially amnesia. [35-37]. Other neurological diseases, such as Alzheimer's disease [38], Parkinson's disease $[39,40]$ and Korsakoff's syndrome [41] also accompany with impaired memory. In addition, a common temporary failure of memory retrieval is often found under some specific situations like emotion [42], aging [43], sleep [44] or other unrealized factors [45, 46]. Therefore, drugs facilitating information process, consolidation, store or retrieval may contribute to the improvement of memory deficits under the aforementioned conditions. In our study, ASIV was found to facilitate the memory formation of mice as it promoted reference memory (long-term memory) and working memory (short-term memory) in RAMT, as well as procedural memory (long-term memory) in SBT, suggesting that ASIV might benefit memory loss occurred in neurological disorders.

LTD is the process that reflects the weakening of specific synaptic transmission in order to constructively utilize synaptic reinforcement. It is a necessary process because, if allowed to continue increasing in strength, synapses would ultimately reach a ceiling level of efficiency, which would inhibit the encoding of new information. (Purves D (2008). Neuroscience (4th ed.). Sunderland, Mass: Sinauer. pp. 197-200. ISBN 0-87893-697-1). In this study, ASIV administration was displayed to enhance LTD which was induced by adding $\mathrm{GABA}_{\mathrm{A}}$ receptor blockers bicuculline. Meanwhile, ASIV decreased the hippocampal GABA level as well as the expression of GAD65, suggesting the weakening of GABAergic synaptic transmission, which was further confirmed by the reduced inhibitory synapse ratio. Previous study reported that blockade of GABAergic synaptic transmission enhances memory consolidation [47]. Therefore, our findings indicated that ASIV enhanced memory of mice probably through modulating GABAergic inhibition, thus indirectly enhanced synaptic plasticity.

Expression of EGR-1 is indicated to be associated with LTD of synaptic efficacy. In recent years, the most remarkable conclusion is that EGR-1 not only plays a key role in different forms of memory, but also plays a key role in different processes operating on memory, from post learning memory consolidation and system consolidation to reconsolidation, updating, and extinction [48]. Chemical LTD induced in hippocampal slice cultures was shown to induce the expression of EGR-1[9]. However, in vivo electrophysiological studies reported no evidence that the expression of EGR-1 was regulated after LTD induction in CA1 region [49]. In the study, EGR-1 was found to be decreased in mouse hippocampus after ASIV administration. However, a single-trail of SBT could boost the expression of EGR-1 rapidly. Meanwhile, ASIV administration for two weeks reduced LTD in hippocampal slices. Together, these results implicated that ASIV could decrease the basal level of EGR-1, which in turn increases its activitydependent capacity in response to external stimuli.

Previous studies have shown that expression of GAD65 is likely modulated by BDNF and TrkB at mRNA or protein level [50-52]. It can be imagined that the activity-dependent release of BDNF may affect the inhibition circuit by triggering GAD 65 transcription, thereby increasing the synaptic level of GABA, thereby regulating the activity of neural networks[53]. Here we described that BDNF/TrkB was decreased together 
with the GABAergic inhibition of ASIV and this effect was blocked by EGR-1 knockout. Therefore, it might be possible that ASIV treatment decreased the expression levels of BDNF/TrkB rather favor a reduction for the GAD65 probably by inhibition of the EGR-1 activity.

Together, ASIV could enhance the memory of mice and improve hippocampal synaptic plasticity, which might be achieved through modulating hippocampal GABAergic inhibition mediated EGR-1. Our current work benefits for the clinical application of ASIV in the prevention and treatment of memory-related diseases.

\section{Declarations}

\section{Ethics approval and consent to participate}

All experiments on animals were performed according to the protocol approved by Animal Care and Use Committee of SHUTCM and all animals received humane care (Ethical approval no. SZY201610005). The animal-related procedures we studied are in accordance with the 1975 Declaration of Helsinki on animal rights (as revised in 2008).

\section{Consent for publication}

Not applicable.

\section{Availability of data and material}

The datasets used and analyzed during the current study are available from the corresponding author on reasonable request.

\section{Competing of interests}

The authors declare that they have no competing interests.

\section{Funding}

This work was supported by National Natural Science Foundation of China (W.X. No. 81673626, China).

\section{Authors' contributions}

Funding acquisition, Fei Huang and Xiaojun Wu; Investigation, Fei Huang, Jin Zhou, Yunyi Lan, Liu Yang and Hao Guan; Methodology, Hui Wu and Hailian Shi; Supervision, Zhibi Hu and Xiaojun Wu; Writing original draft, Fei Huang; Writing - review \& editing, Xiaojun Wu.

\section{Acknowledgements}

Not applicable. 


\section{References}

1. Buffington SA, Huang W, Costa-Mattioli M. Translational control in synaptic plasticity and cognitive dysfunction. Annu Rev Neurosci. 2014;37:17-38. doi: 10.1146/annurev-neuro-071013-014100.

2. Wagner JJ, Alger BE. GABAergic and developmental influences on homosynaptic LTD and depotentiation in rat hippocampus. J Neurosci. 1995;15(2):1577-86.

3. Brady ML, Pilli J, Lorenz-Guertin JM, Das S, Moon CE, Graff N, et al. Depolarizing, inhibitory GABA type A receptor activity regulates GABAergic synapse plasticity via ERK and BDNF signaling. Neuropharmacology. 2018;128:324-39. doi: 10.1016/j.neuropharm.2017.10.022.

4. Mitchell JJ, Paiva M, Walker DW, Heaton MB. BDNF and NGF afford in vitro neuroprotection against ethanol combined with acute ischemia and chronic hypoglycemia. Dev Neurosci. 1999;21(1):68-75. doi: 17368 [pii] 17368.

5. Scharfman HE. Brain-derived neurotrophic factor and epilepsy-a missing link? Epilepsy Curr. 2005;5(3):83-8. doi: 10.1111/j.1535-7511.2005.05312.x.

6. Sukhatme VP, Cao XM, Chang LC, Tsai-Morris CH, Stamenkovich D, Ferreira PC, et al. A zinc fingerencoding gene coregulated with c-fos during growth and differentiation, and after cellular depolarization. Cell. 1988;53(1):37-43.

7. Cole AJ, Saffen DW, Baraban JM, Worley PF. Rapid increase of an immediate early gene messenger RNA in hippocampal neurons by synaptic NMDA receptor activation. Nature. 1989;340(6233):474-6. doi: $10.1038 / 340474 a 0$.

8. Wisden W, Errington ML, Williams S, Dunnett SB, Waters C, Hitchcock D, et al. Differential expression of immediate early genes in the hippocampus and spinal cord. Neuron. 1990;4(4):603-14.

9. Lindecke A, Korte M, Zagrebelsky M, Horejschi V, Elvers M, Widera D, et al. Long-term depression activates transcription of immediate early transcription factor genes: involvement of serum response factor/Elk-1. Eur J Neurosci. 2006;24(2):555-63. doi: 10.1111/j.1460-9568.2006.04909.x.

10. Xie L, Korkmaz KS, Braun K, Bock J. Early life stress-induced histone acetylations correlate with activation of the synaptic plasticity genes Arc and Egr1 in the mouse hippocampus. J Neurochem. 2013;125(3):457-64. doi: 10.1111/jnc.12210.

11. Zhao Z, Fan L, Fortress AM, Boulware MI, Frick KM. Hippocampal histone acetylation regulates object recognition and the estradiol-induced enhancement of object recognition. J Neurosci. 2012;32(7):2344-51. doi: 10.1523/JNEUROSCI.5819-11.2012.

12. Hall J, Thomas KL, Everitt BJ. Cellular imaging of zif268 expression in the hippocampus and amygdala during contextual and cued fear memory retrieval: selective activation of hippocampal CA1 neurons during the recall of contextual memories. J Neurosci. 2001;21(6):2186-93.

13. Maviel T, Durkin TP, Menzaghi F, Bontempi B. Sites of neocortical reorganization critical for remote spatial memory. Science. 2004;305(5680):96-9. doi: 10.1126/science.1098180.

14. Besnard A, Laroche S, Caboche J. Comparative dynamics of MAPK/ERK signalling components and immediate early genes in the hippocampus and amygdala following contextual fear conditioning 
and retrieval. Brain Struct Funct. 2014;219(1):415-30. doi: 10.1007/s00429-013-0505-y.

15. Cheval H, Chagneau C, Levasseur G, Veyrac A, Faucon-Biguet N, Laroche S, et al. Distinctive features of Egr transcription factor regulation and DNA binding activity in CA1 of the hippocampus in synaptic plasticity and consolidation and reconsolidation of fear memory. Hippocampus. 2012;22(3):631-42. doi: 10.1002/hipo.20926.

16. He Y, Du M, Gao Y, Liu H, Wang H, Wu X, et al. Astragaloside IV attenuates experimental autoimmune encephalomyelitis of mice by counteracting oxidative stress at multiple levels. PLoS One. 2013;8(10):e76495. doi: 10.1371/journal.pone.0076495 PONE-D-13-10017 [pii].

17. Kim MH, Kim SH, Yang WM. Beneficial effects of Astragaloside IV for hair loss via inhibition of Fas/Fas L-mediated apoptotic signaling. PLoS One. 2014;9(3):e92984. doi:

10.1371/journal.pone.0092984 PONE-D-13-50848 [pii].

18. Wang B, Chen MZ. Astragaloside IV possesses antiarthritic effect by preventing interleukin 1 betainduced joint inflammation and cartilage damage. Arch Pharm Res. 2014;37(6):793-802. doi: 10.1007/s12272-014-0336-2.

19. Hong F, Xiao W, Ragupathi G, Lau CB, Leung PC, Yeung KS, et al. The known immunologically active components of Astragalus account for only a small proportion of the immunological adjuvant activity when combined with conjugate vaccines. Planta Med. 2011;77(8):817-24. doi: 10.1055/s0030-1250574.

20. Yang L, Xing F, Han X, Li Q, Wu H, Shi H, et al. Astragaloside IV regulates differentiation and induces apoptosis of activated CD4(+) T cells in the pathogenesis of experimental autoimmune encephalomyelitis. Toxicol Appl Pharmacol. 2019;362:105-15. doi: 10.1016/j.taap.2018.10.024.

21. Luo Y, Qin Z, Hong Z, Zhang X, Ding D, Fu JH, et al. Astragaloside IV protects against ischemic brain injury in a murine model of transient focal ischemia. Neurosci Lett. 2004;363(3):218-23. doi: 10.1016/j.neulet.2004.03.036 S0304394004003362 [pii].

22. Qu YZ, Li M, Zhao YL, Zhao ZW, Wei XY, Liu JP, et al. Astragaloside IV attenuates cerebral ischemiareperfusion-induced increase in permeability of the blood-brain barrier in rats. Eur J Pharmacol. 2009;606(1-3):137-41. doi: S0014-2999(09)00065-X [pii] 10.1016/j.ejphar.2009.01.022.

23. Yang J, Li J, Lu J, Zhang Y, Zhu Z, Wan H. Synergistic protective effect of astragaloside IVtetramethylpyrazine against cerebral ischemic-reperfusion injury induced by transient focal ischemia. J Ethnopharmacol. 2012;140(1):64-72. doi: S0378-8741(11)00901-9 [pii] 10.1016/j.jep.2011.12.023.

24. Zhang ZG, Wu L, Wang JL, Yang JD, Zhang J, Li LH, et al. Astragaloside IV prevents MPP(+)-induced SH-SY5Y cell death via the inhibition of Bax-mediated pathways and ROS production. Mol Cell Biochem. 2012;364(1-2):209-16. doi: 10.1007/s11010-011-1219-1.

25. Haiyan H, Rensong Y, Guoqin J, Xueli Z, Huaying X, Yanwu X. Effect of Astragaloside IV on Neural Stem Cell Transplantation in Alzheimer's Disease Rat Models. Evid Based Complement Alternat Med. 2016;2016:3106980. doi: 10.1155/2016/3106980.

26. Wang X, Wang Y, Hu JP, Yu S, Li BK, Cui Y, et al. Astragaloside IV, a Natural PPARgamma Agonist, Reduces Abeta Production in Alzheimer's Disease Through Inhibition of BACE1. Mol Neurobiol. 
2017;54(4):2939-49. doi: 10.1007/s12035-016-9874-6.

27. Zheng F, Zhou Q, Cao Y, Shi H, Wu H, Zhang B, et al. P2Y12 deficiency in mouse impairs noradrenergic system in brain, and alters anxiety-like neurobehavior and memory. Genes Brain Behav. 2018. doi: $10.1111 / \mathrm{gbb} .12458$.

28. Cheng XR, Yang Y, Zhou WX, Zhang YX. Expression of VGLUTs contributes to degeneration and acquisition of learning and memory. Neurobiol Learn Mem. 2011;95(3):361-75. doi:

10.1016/j.nlm.2011.01.010.

29. Huang F, Li J, Shi HL, Wang TT, Muhtar W, Du M, et al. Simultaneous quantification of seven hippocampal neurotransmitters in depression mice by LC-MS/MS. J Neurosci Methods. 2014;229:814. doi: S0165-0270(14)00120-4 [pii] 10.1016/j.jneumeth.2014.04.004.

30. Zhang Q, Liu W, Niu Q, Wang Y, Zhao H, Zhang H, et al. Effects of perfluorooctane sulfonate and its alternatives on long-term potentiation in the hippocampus CA1 region of adult rats in vivo. Toxicol Res (Camb). 2016;5(2):539-46. doi: 10.1039/c5tx00184f.

31. Colonnier M. Synaptic patterns on different cell types in the different laminae of the cat visual cortex. An electron microscope study. Brain Res. 1968;9(2):268-87.

32. Peters A, Palay SL. The morphology of synapses. J Neurocytol. 1996;25(12):687-700.

33. DeFelipe J, Marco P, Busturia I, Merchan-Perez A. Estimation of the number of synapses in the cerebral cortex: methodological considerations. Cereb Cortex. 1999;9(7):722-32.

34. Missaire M, Fraize N, Joseph MA, Hamieh AM, Parmentier R, Marighetto A, et al. Long-term effects of interference on short-term memory performance in the rat. PLoS One. 2017;12(3):e0173834. doi: 10.1371/journal.pone.0173834.

35. Aparicio-Nava L, Tellez R, Gonzalez R, Liy-Salmeron G, Meneses A. Intrahippocampal administration of 5-HT6 receptor drugs on memory consolidation and amnesia protocols. Behav Brain Res. 2019;359:378-85. doi: 10.1016/j.bbr.2018.11.021.

36. Ishola IO, Jacinta AA, Adeyemi 00. Cortico-hippocampal memory enhancing activity of hesperetin on scopolamine-induced amnesia in mice: role of antioxidant defense system, cholinergic neurotransmission and expression of BDNF. Metab Brain Dis. 2019. doi: 10.1007/s11011-019-004090 .

37. Madsen HB, Kim JH. Ontogeny of memory: An update on 40 years of work on infantile amnesia. Behav Brain Res. 2016;298(Pt A):4-14. doi: 10.1016/j.bbr.2015.07.030.

38. Bastin C, Delhaye E, Moulin C, Barbeau EJ. Novelty processing and memory impairment in Alzheimer's disease: A review. Neurosci Biobehav Rev. 2019;100:237-49. doi: 10.1016/j.neubiorev.2019.02.021.

39. Ramanan S, Kumar D. Prospective memory in Parkinson's disease: a meta-analysis. J Int Neuropsychol Soc. 2013;19(10):1109-18. doi: 10.1017/S1355617713001045.

40. Ringendahl H. [Memory disturbances in Parkinson's disease]. Fortschr Neurol Psychiatr. 1996;64(2):43-8. doi: 10.1055/s-2007-996371. 
41. Race $E$, Verfaellie M. Remote memory function and dysfunction in Korsakoff's syndrome. Neuropsychol Rev. 2012;22(2):105-16. doi: 10.1007/s11065-012-9197-y.

42. Tyng CM, Amin HU, Saad MNM, Malik AS. The Influences of Emotion on Learning and Memory. Front Psychol. 2017;8:1454. doi: 10.3389/fpsyg.2017.01454.

43. van der Zee EA. Synapses, spines and kinases in mammalian learning and memory, and the impact of aging. Neurosci Biobehav Rev. 2015;50:77-85. doi: 10.1016/j.neubiorev.2014.06.012.

44. Koyanagi I, Akers KG, Vergara P, Srinivasan S, Sakurai T, Sakaguchi M. Memory consolidation during sleep and adult hippocampal neurogenesis. Neural Regen Res. 2019;14(1):20-3. doi: 10.4103/16735374.243695.

45. Crowley R, Bendor D, Javadi AH. A review of neurobiological factors underlying the selective enhancement of memory at encoding, consolidation, and retrieval. Prog Neurobiol. 2019. doi: 10.1016/j.pneurobio.2019.04.004.

46. Torres-Berrio A, Nava-Mesa MO. The opioid system in stress-induced memory disorders: From basic mechanisms to clinical implications in post-traumatic stress disorder and Alzheimer's disease. Prog Neuropsychopharmacol Biol Psychiatry. 2019;88:327-38. doi: 10.1016/j.pnpbp.2018.08.011.

47. Kim DH, Kim JM, Park SJ, Cai M, Liu X, Lee S, et al. GABA(A) receptor blockade enhances memory consolidation by increasing hippocampal BDNF levels. Neuropsychopharmacology. 2012;37(2):42233. doi: 10.1038/npp.2011.189.

48. Veyrac A, Besnard A, Caboche J, Davis S, Laroche S. The transcription factor Zif268/Egr1, brain plasticity, and memory. Prog Mol Biol Transl Sci. 2014;122:89-129. doi: 10.1016/B978-0-12-4201705.00004-0.

49. Yilmaz-Rastoder E, Miyamae T, Braun AE, Thiels E. LTP- and LTD-inducing stimulations cause opposite changes in arc/arg3.1 mRNA level in hippocampal area CA1 in vivo. Hippocampus. 2011;21(12):1290-301. doi: 10.1002/hipo.20838.

50. Carmona MA, Martinez A, Soler A, Blasi J, Soriano E, Aguado F. Ca(2+)-evoked synaptic transmission and neurotransmitter receptor levels are impaired in the forebrain of trkb (-/-) mice. Mol Cell Neurosci. 2003;22(2):210-26.

51. Carmona MA, Pozas E, Martinez A, Espinosa-Parrilla JF, Soriano E, Aguado F. Age-dependent spontaneous hyperexcitability and impairment of GABAergic function in the hippocampus of mice lacking trkB. Cereb Cortex. 2006;16(1):47-63. doi: 10.1093/cercor/bhi083.

52. Rico B, Xu B, Reichardt LF. TrkB receptor signaling is required for establishment of GABAergic synapses in the cerebellum. Nat Neurosci. 2002;5(3):225-33. doi: 10.1038/nn808.

53. Sanchez-Huertas C, Rico B. CREB-Dependent Regulation of GAD65 Transcription by BDNF/TrkB in Cortical Interneurons. Cereb Cortex. 2011;21(4):777-88. doi: 10.1093/cercor/bhq150.

\section{Figures}


A

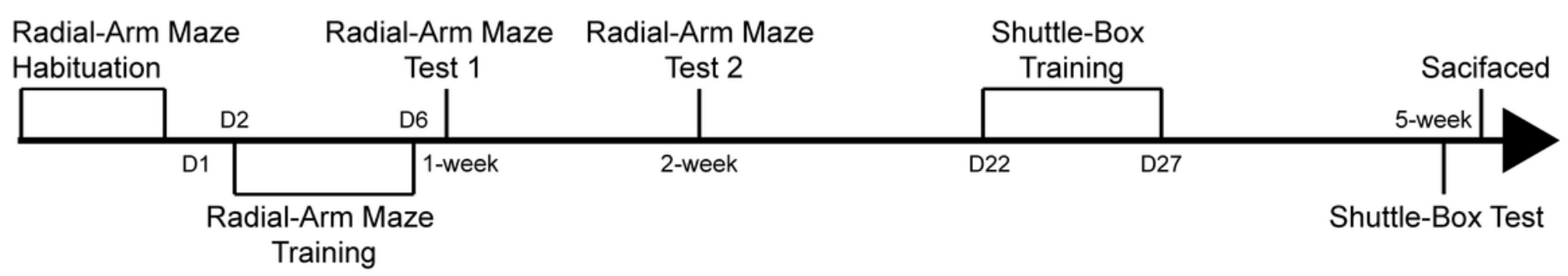

B

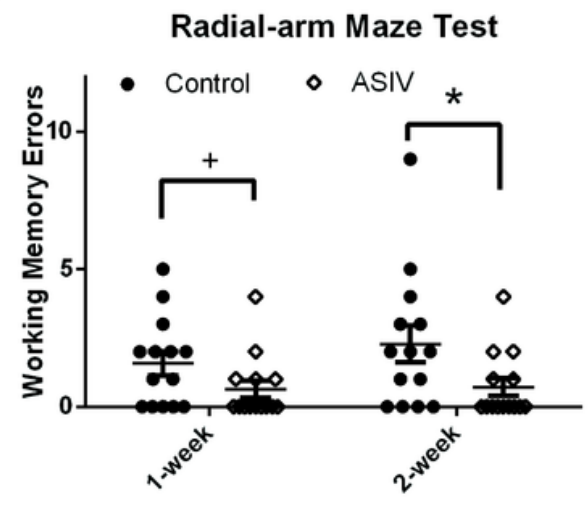

$\mathrm{C}$ Radial-arm Maze Test

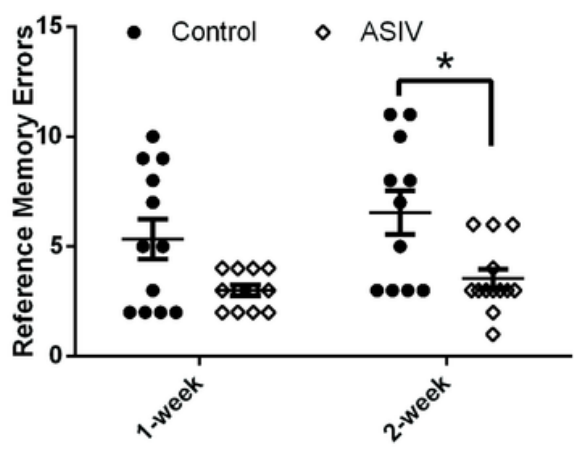

$\mathrm{D}$

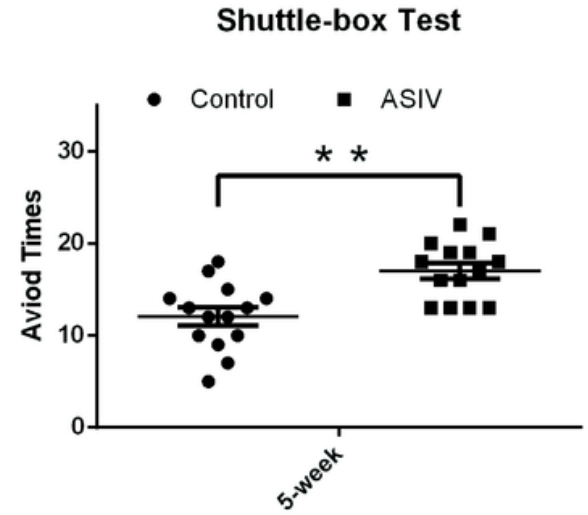

Figure 1

Effects of ASIV on memory of mice in behavior tests. (A) Timeline for RAMT and SBT. (B) Working memory errors of RAMT. The mice administered ASIV performed lower times of errors than control group mice for 2-week and a lower time tendency for 1-week; (C) Reference memory errors of RAMT. The mice administered ASIV performed lower times of errors than control group mice for 2-week and a lower time tendency for 1-week; (D) Avoid times of SBT. The mice administered ASIV performed higher numbers of avoid times than control group mice. $n=14$ /group. $+P<0.1$, ${ }^{\star} P<0.05$, ${ }^{\star *} P<0.01$, the data are shown as the mean \pm S.E.M. 
A

\section{GABA in mouse hippocampus}

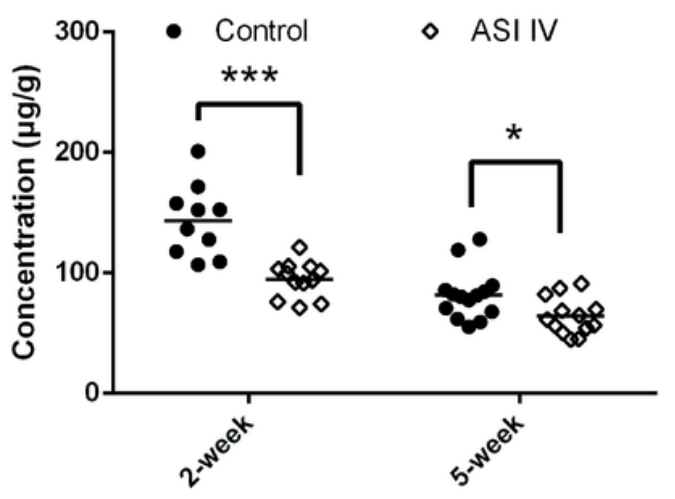

B
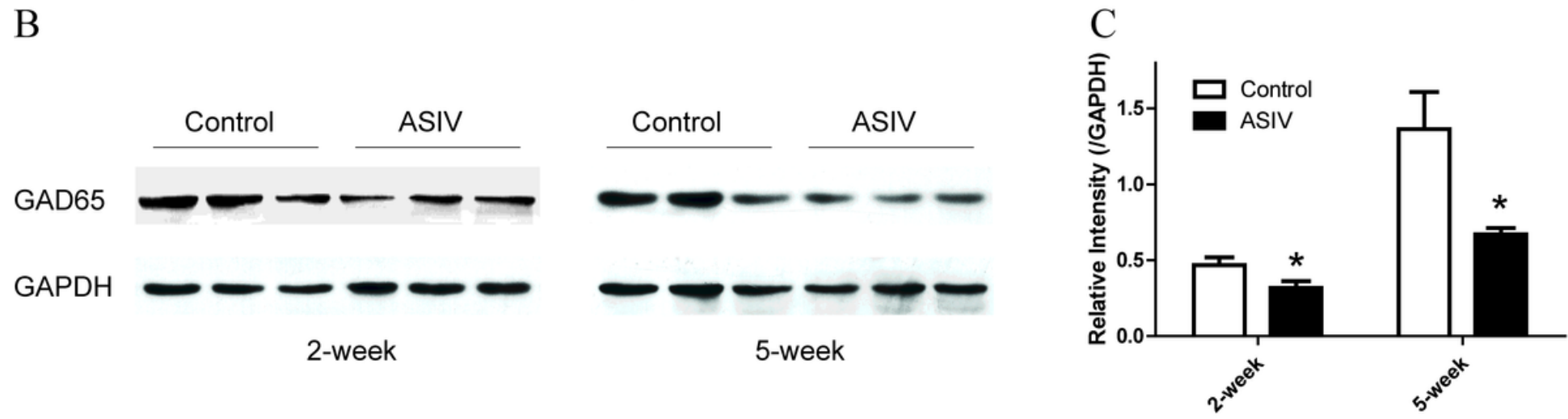

D

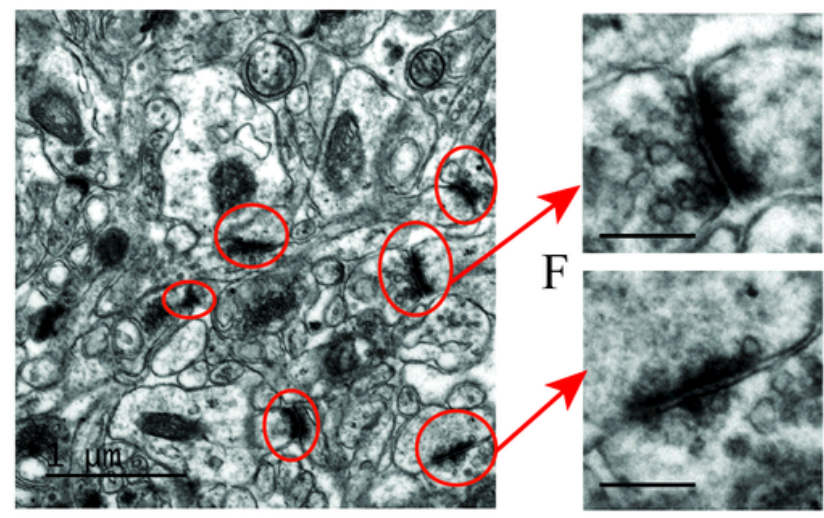

$\mathrm{E}$

Excitatory synapse

Inhibitory synapse
G

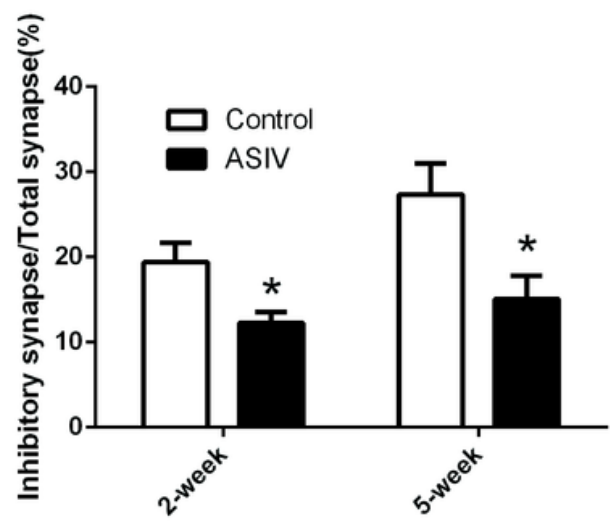

Figure 2

Effects of ASIV on GABAergic inhibition in mouse hippocampus. (A) Concentration of GABA in the hippocampus. ASIV administration decreased the GABA in mice hippocampus both for 2-week and 5week, $n$ = 12/group; (B) GAD65 protein expression level in the hippocampus, $n=4 /$ group; (C) Gray intensity analysis of the GAD65 in the hippocampus, ASIV administration decreased the GAD65 in mice hippocampus both for 2-week and 5-week, $n=4$ /group. (D) Electron microscopy of CA3 area of hippocampus, scale bar $=1 \mu \mathrm{m}$; $(E)$ The enlarge picture of excitatory synapse, scale bar $=0.2 \mu \mathrm{m}$; $(F)$ The enlarge picture of inhibitory synapse, scale bar $=0.2 \mu \mathrm{m} ;(\mathrm{G})$ The ratio of inhibitory synapse in total synapse, ASIV administration decreased the ratio of inhibitory synapse/total synapse in mice 
hippocampus both for 2-week and 5-week, $n=4$ /group. ${ }^{*} P<0.05$, ${ }^{\star *} P<0.01$, the data are shown as the mean \pm S.E.M.

A
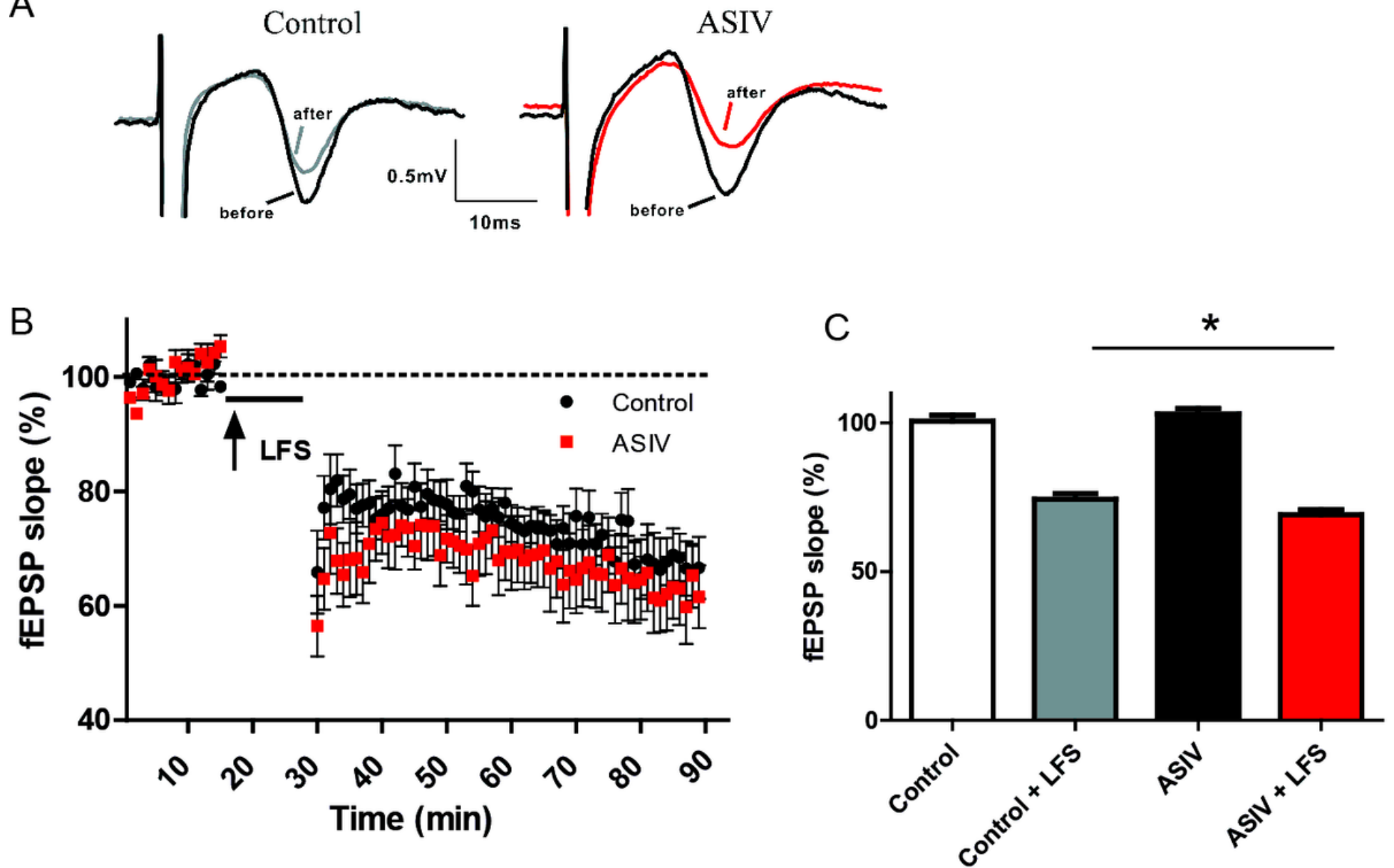

Figure 3

Effects of ASIV on bicuculline-induced alterations of LTD in mouse hippocampal CA1 subfield. (A) Typical fEPSP waveforms before (black lines, "Pre") and after (red lines, "Post") LFS was indicated; (B) Time course of \% fEPSP slopes. Red line indicates the two weeks' application of ASIV; (C) Comparison of \% fEPSP between the control versus ASIV group and between the control versus ASIV group (After LFS), significant difference between the control versus ASIV group after LFS. $n=4 /$ group, $* P<0.05$, the data are shown as the mean \pm S.E.M. 


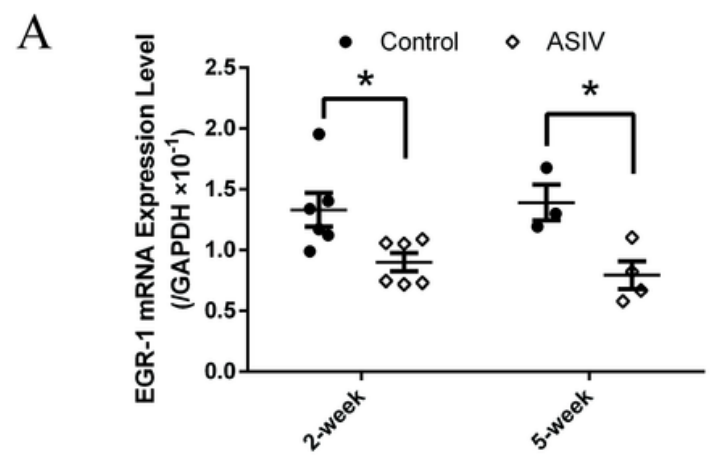

B

$\mathrm{C}$
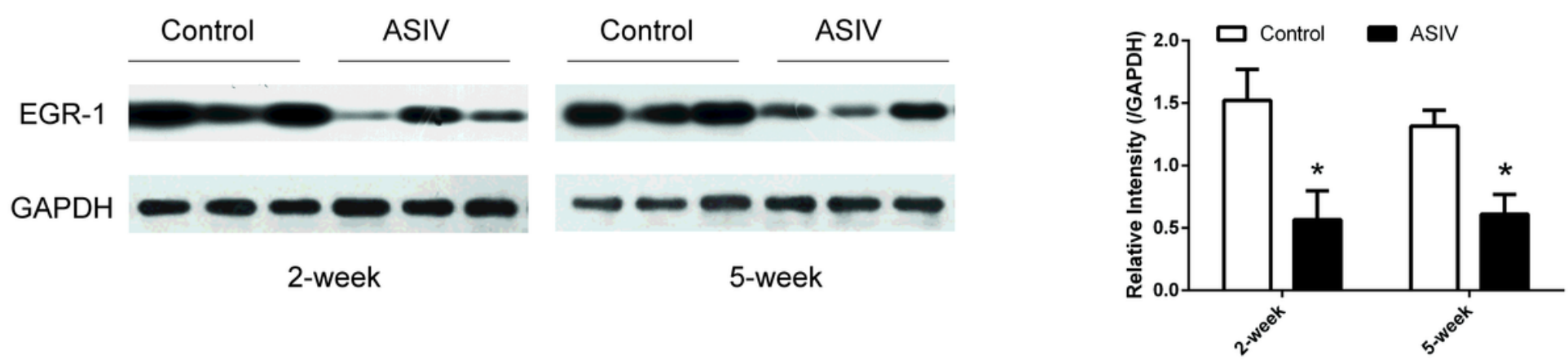

Figure 4

Effects of ASIV on expression of EGR-1 in mice hippocampus. (A) EGR-1 mRNA expression level, ASIV administration decreased the EGR-1 mRNA expression in mice hippocampus both for 2-week and 5-week, $n=4 /$ group; (B) Western blotting analysis of EGR-1; (C) Gray intensity comparison of EGR-1, ASIV administration decreased the EGR-1 protein expression in mice hippocampus both for 2-week and 5-week. $n=4 /$ group, ${ }^{*} P<0.05, * \star, P<0.01$, the data are shown as the mean \pm S.E.M. 
A

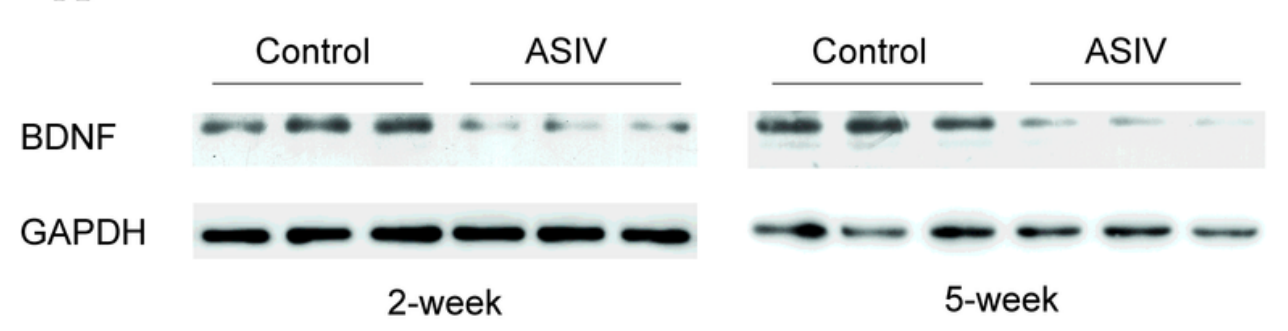

$\mathrm{C}$

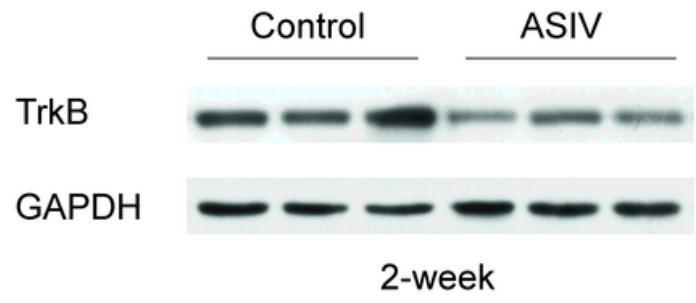

B

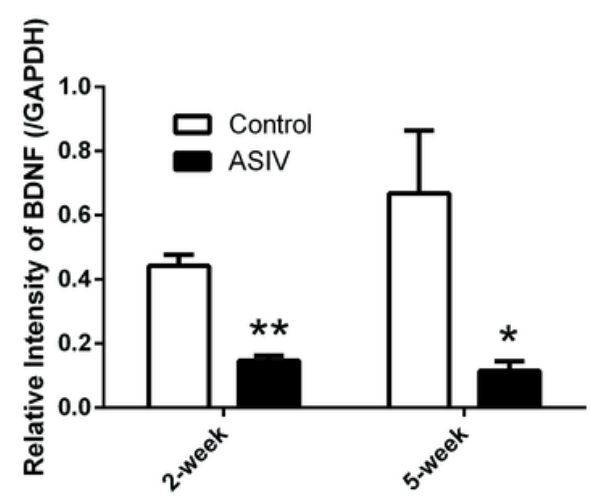

$\mathrm{D}$
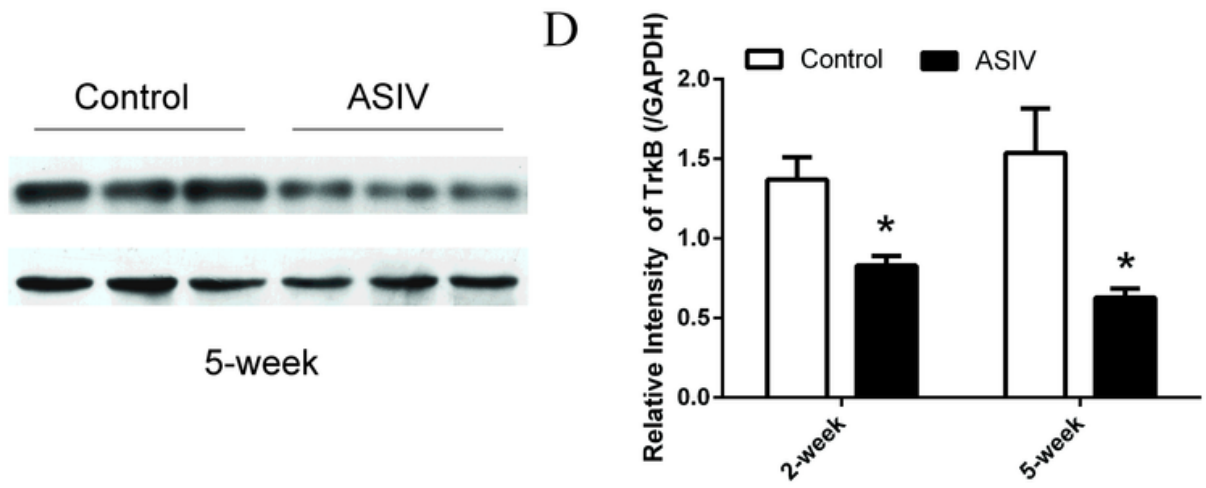

Figure 5

Effects of ASIV on BDNF/TrkB in hippocampus of mice. (A) Western blotting analysis of BDNF; (B) Gray intensity comparison of BDNF. ASIV administration decreased the BDNF protein expression in mice hippocampus both for 2-week and 5-week; (C) Western blotting analysis of TrkB; (D) Gray intensity comparison of TrkB. ASIV administration decreased the TrkB protein expression in mice hippocampus both for 2 -week and 5-week. $n=4$ /group, ${ }^{*} P<0.05$, $* *, P<0.01$, the data are shown as the mean \pm S.E.M..

A

\section{Radial-arm Maze Test}

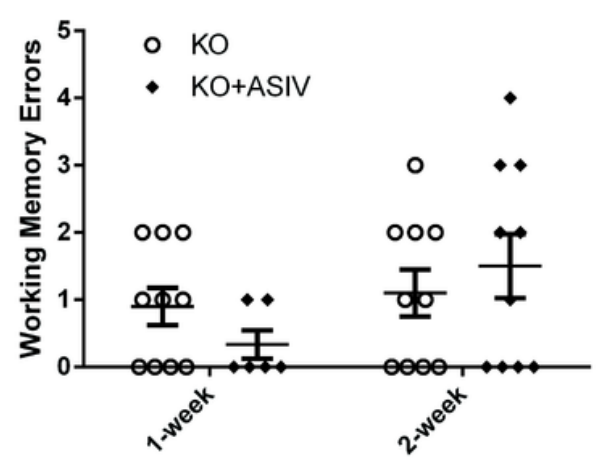

$\mathrm{B}$

Radial-arm Maze Test

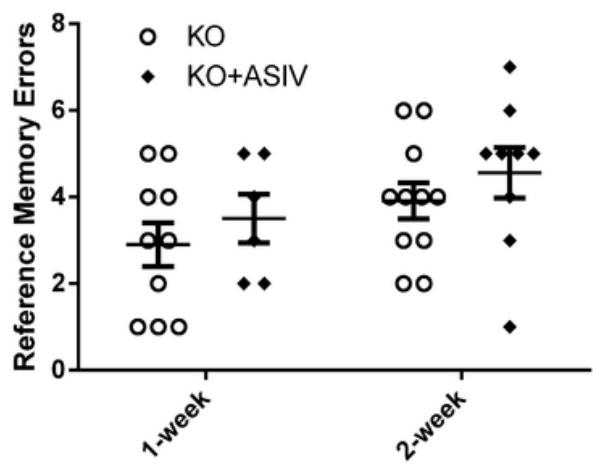

C

Shuttle-box test

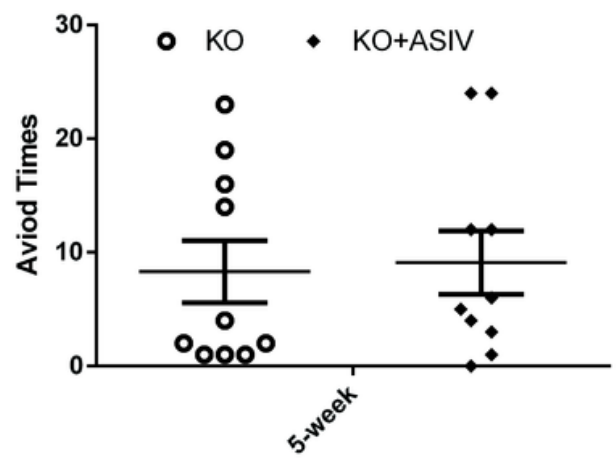

Figure 6

Effects of ASIV on memory of EGR-1 KO mice in behavior tests. (A) Working memory errors of mice in RAMT. (B) Reference memory errors of mice in RAMT. (C) The active avoidance times of mice in SBT. The 
KO mice administered ASIV performed no significant difference both in RAMT and SBT. $n=14$ /group, the data are shown as the mean \pm S.E.M..

A

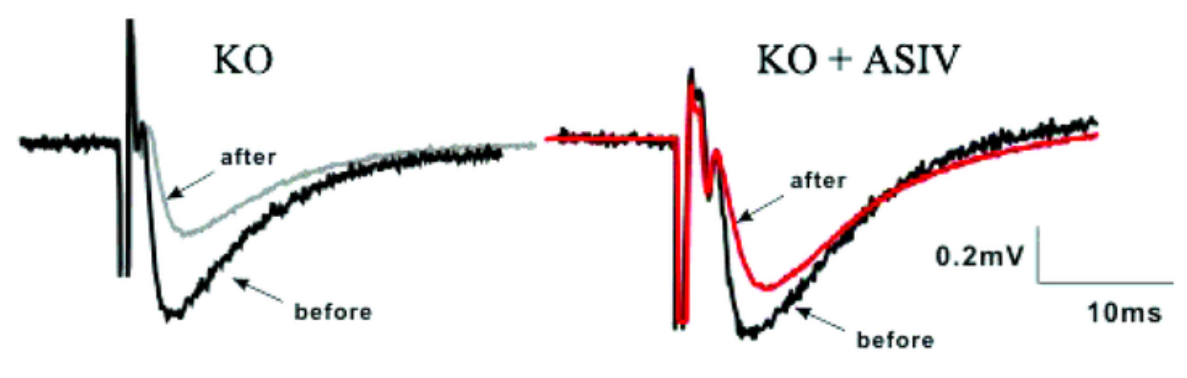

B

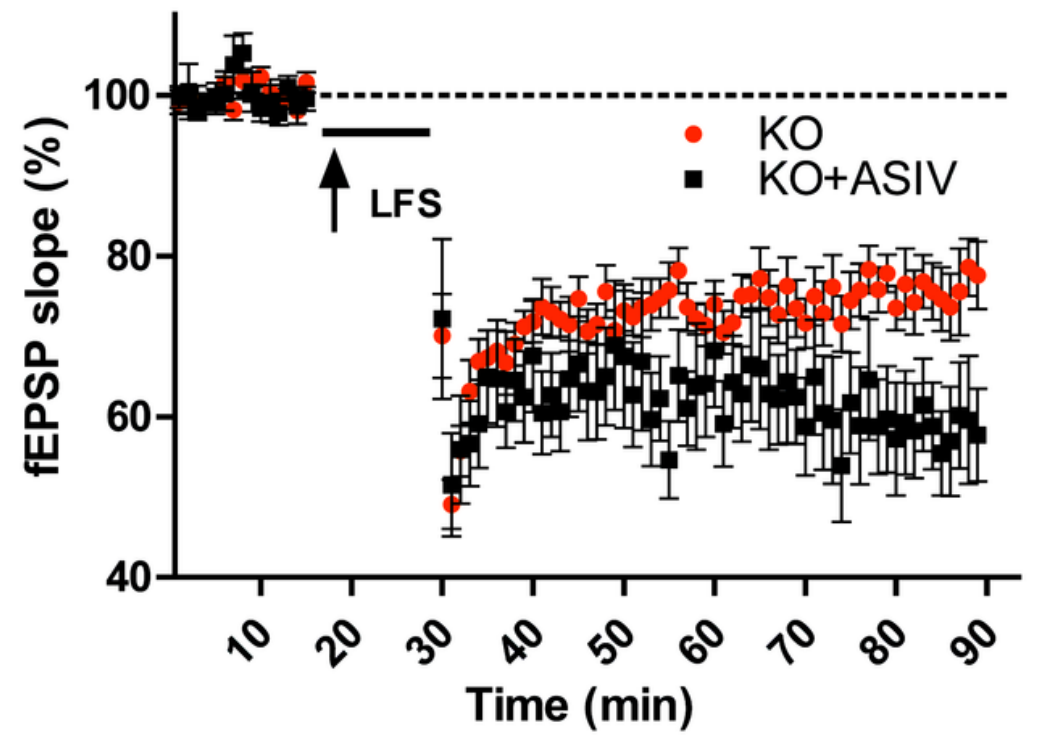

$\mathrm{C}$

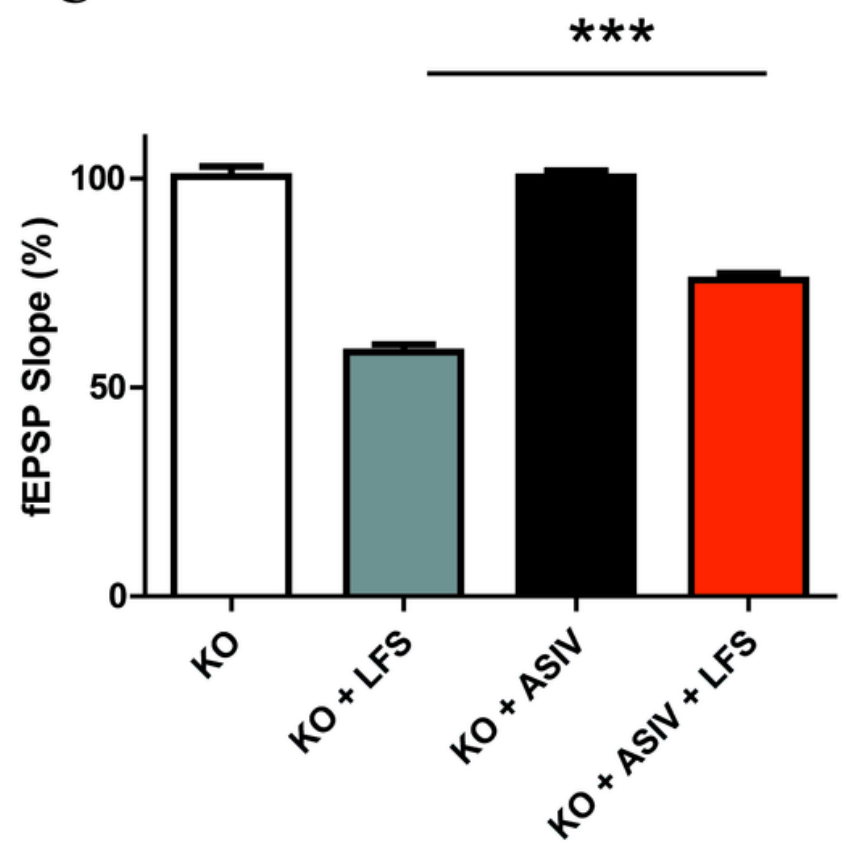

Figure 7

Effects of ASIV on bicuculline-induced alterations of LTD in mouse hippocampal CA1 subfield. (A) Typical fEPSP waveforms before (black lines, “Pre”) and after (red lines, "Post”) LFS was indicated. (B) Time course of \% fEPSP slopes. Red line indicates the 2 weeks application of ASIV. (C) Comparison of \% fEPSP between the KO versus KO+ASIV groups and between the control versus ASIV groups (After LFS), Significant difference between the control versus KO versus KO+ASIV groups after LFS $(P<0.001)$. $n=$ $4 /$ group, ${ }^{\star \star \star}, \mathrm{P}<0.001$, the data are shown as the mean \pm S.E.M.. 
A

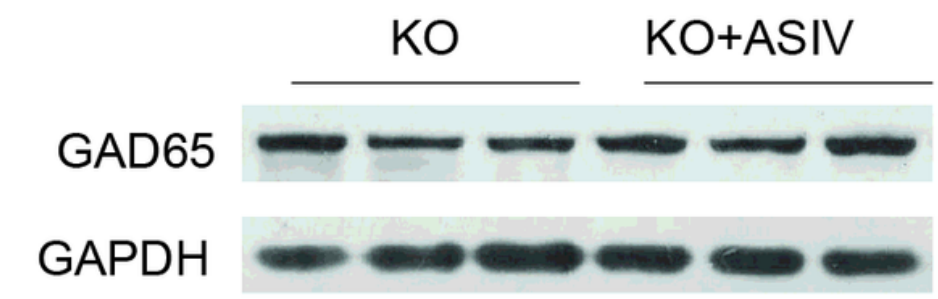

$\mathrm{C}$
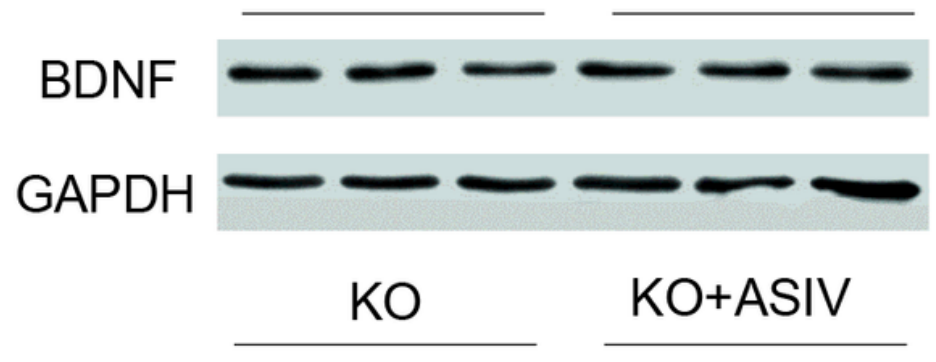

TrkB

GAPDH
$\mathrm{B}$

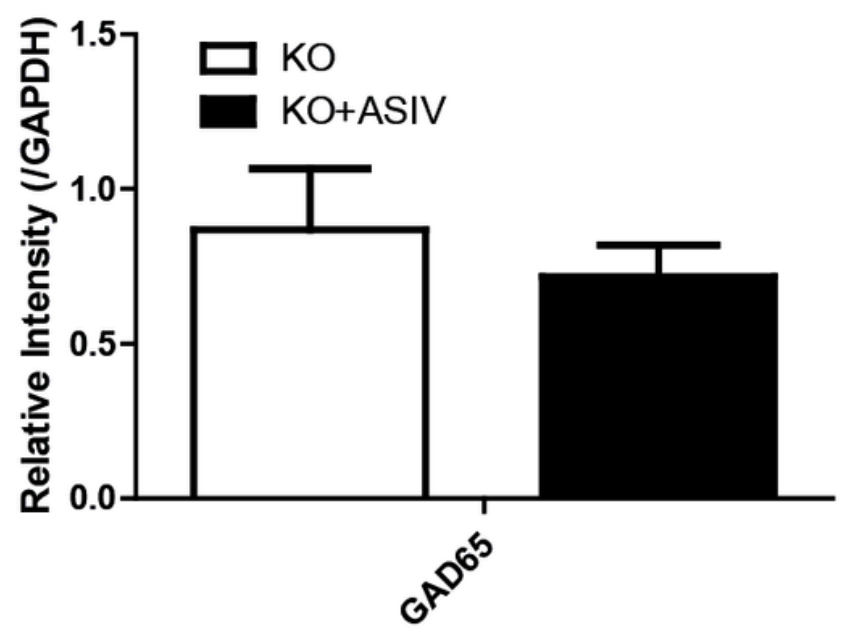

$\mathrm{D}$

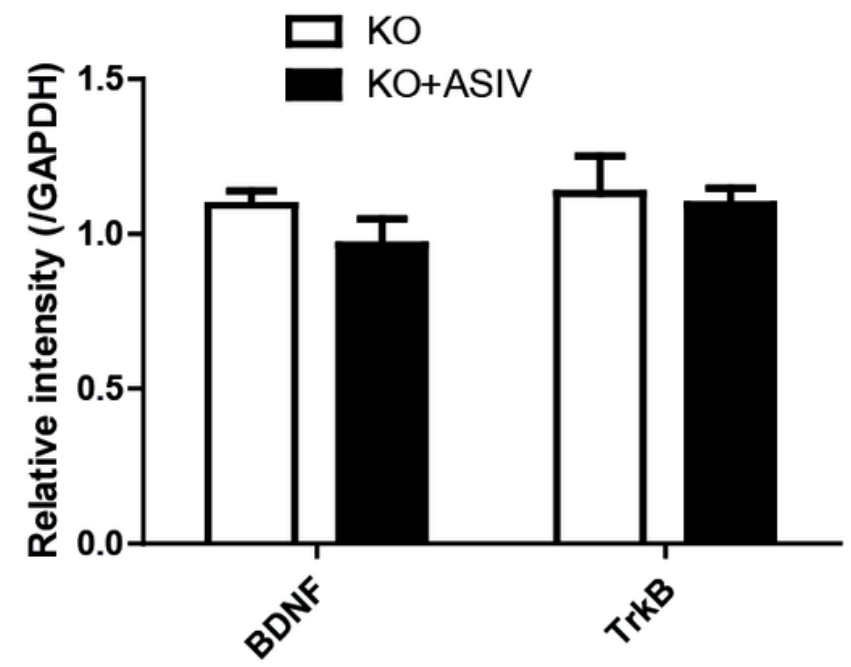

Figure 8

Effects of ASIV on GAD65, BDNF and TrkB in hippocampus of EGR-1 KO mice. (A) Western blotting analysis of GAD65; (B) Gray intensity comparison GAD65; (C) Western blotting analysis of GAD65; (D) Gray intensity comparison of BDNF and TrkB. Administered ASIV had no effect on GAD65, BDNF and TrkB in hippocampus of EGR-1 KO mice of. $n=4$ /group, the data are shown as the mean \pm S.E.M. 
A

\section{The Input-Output curves}

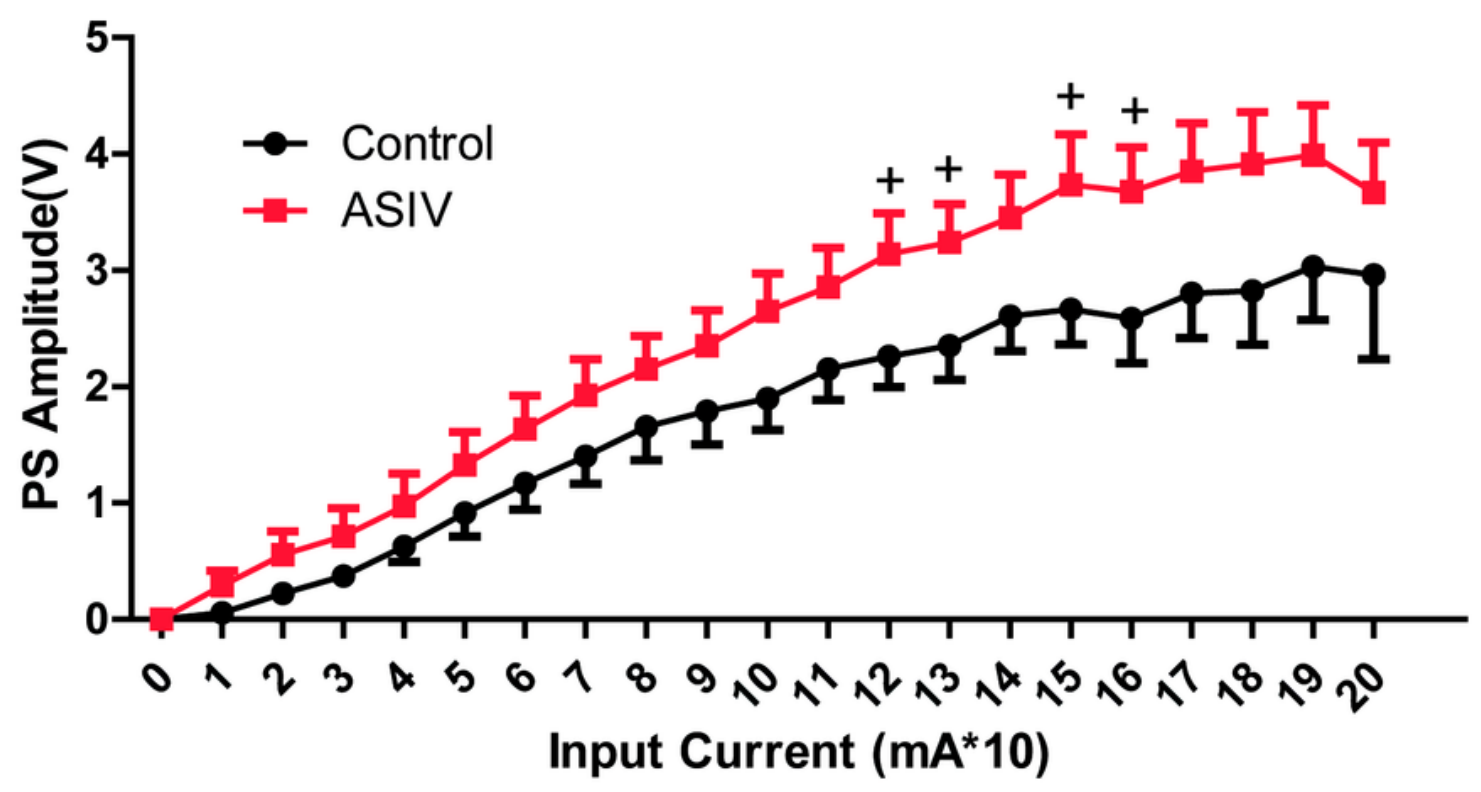

$\mathrm{B}$

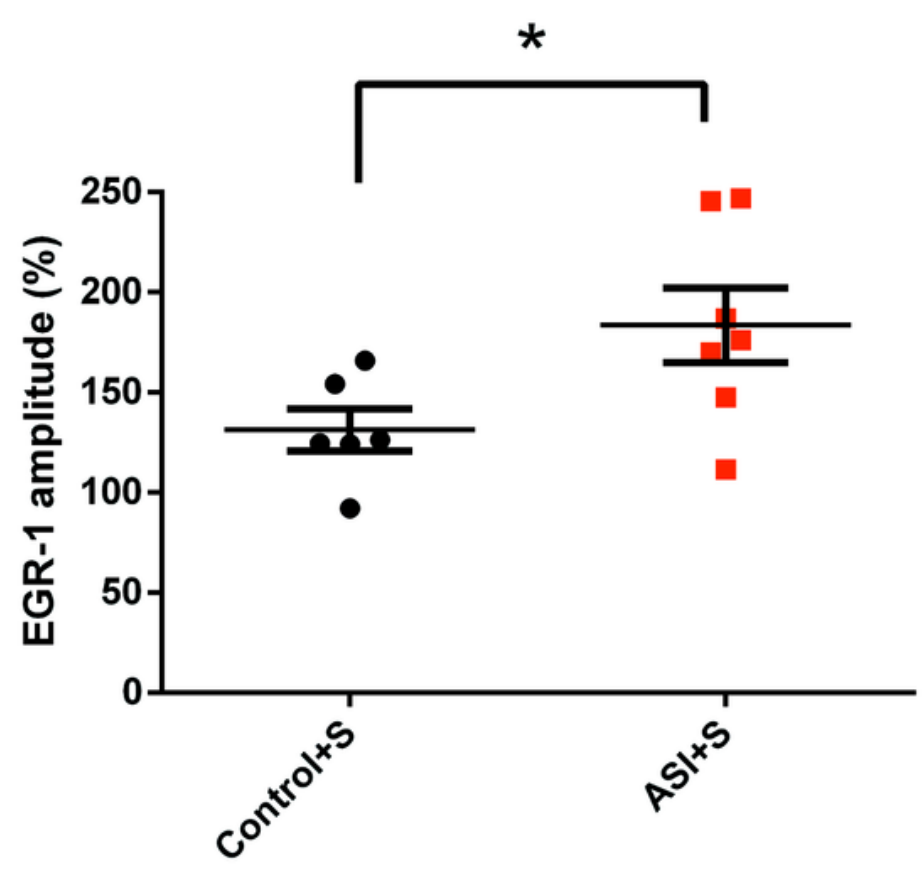

Figure 9

Effects of ASIV on response of mice to stimulation. (A) I/O curves of PS amplitude at varying stimulus current of 0.1-2.0 mA in the hippocampus CA1 region in vivo. Red line indicates the 2 weeks application of ASIV. $n=10 /$ group; (B) Comparing the amplitude of EGR-1 expression in hippocampus after ASIV administration with that in control group after single shuttle box test. $n=10 /$ group; $+P<0.1$; ${ }^{*}<0.05$, the data are shown as the mean \pm S.E.M.. 


\section{Supplementary Files}

This is a list of supplementary files associated with this preprint. Click to download.

- OnlineFig1020190603.Png 